\title{
Clinical Decision Support Tool for Parental Tobacco Treatment in Hospitalized Children
}

Brian P Jenssen 1,2; Eric D Shelov²; Christopher P Bonafide2; Steven L Bernstein ${ }^{3}$; Alexander G Fiks²; Tyra Bryant-Stephens²

${ }^{1}$ Robert Wood Johnson Foundation Clinical Scholars Program, University of Pennsylvania, Philadelphia, PA;

2Department of Pediatrics, Perelman School of Medicine at the University of Pennsylvania and The Children's Hospital of Philadelphia, Philadelphia, PA;

${ }^{3}$ Department of Emergency Medicine, Department of Health Policy, Yale School of Public Health, Yale Cancer Canter and Yale School of Medicine, New Haven, CT

\section{Keywords}

Clinical decision support, secondhand smoke exposure, tobacco, usability

\section{Summary}

Objectives: To create and evaluate the feasibility, acceptability, and usability of a clinical decision support (CDS) tool within the electronic health record (EHR) to help pediatricians provide smoking cessation counseling and treatment to parents of hospitalized children exposed to secondhand smoke (SHS).

Methods: Mixed method study of first-year pediatric residents on one inpatient unit. Residents received training in smoking cessation counseling, nicotine replacement therapy (NRT) prescribing, and use of a CDS tool to aid in this process. The tool, which alerted when a patient was identified as exposed to SHS based on the history taken on admission or during a prior encounter, had the following capabilities: adding SHS exposure to the patient's problem list; referral to Free Quitline through discharge instructions; and linking to a printable NRT prescription form. We measured feasibility by EHR utilization data. We measured acceptability and usability of the tool by administering questionnaires to residents.

Results: From June-August 2015, the alert triggered for 106 patients, and the tool was used for 52 (49\%) patients. 41 (39\%) patients had SHS exposure added to the problem list, 34 (32\%) parents were referred to the Quitline through discharge instructions, and $15(14 \%)$ parents were prescribed NRT. 10 out of 15 (67\%) eligible pediatricians used the tool. All clinicians surveyed (9 out of 10) found the tool acceptable and rated its usability good to excellent (average System Usability Scale score was 85 out of $100,95 \% \mathrm{Cl}, 76-93)$.

Conclusions: A non-interruptive CDS tool to help residents provide smoking cessation counseling in the hospital was feasible, acceptable, and usable. Future work will investigate impacts on patient outcomes.

\section{Correspondence to:}

Brian Jenssen, MD

Robert Wood Johnson Foundation Clinical Scholars

Program, University of Pennsylvania, Philadelphia, Pennsylvania

1310 Blockley Hall, 423 Guardian Drive

Philadelphia, PA 19104

215-573-2740 (p)

215-573-2742 (f)

Email: jenssenb@email.chop.edu
Appl Clin Inform 2016; 7: 399-411

http://dx.doi.org/10.4338/ACl-2015-12-RA-0169 received: December 7, 2015

accepted: March 3, 2016

published: May 25, 2016

Citation: Jenssen BP, Shelov ED, Bonafide CP, Bernstein SL, Fiks AG, Bryant-Stephens T. Clinical Decision Support Tool for Parental Tobacco Treatment in Hospitalized Children. Appl Clin Inform 2016; 7: 399-411 http://dx.doi.org/10.4338/ACl-2015-12-RA-0169 


\section{Background}

Secondhand smoke (SHS) exposure is a significant public health problem with clear negative impacts on children's health, including increased risk of asthma exacerbation, hospitalization, and premature death [1-3]. While $17 \%$ of US adults smoke cigarettes [4], more than $40 \%$ of US children have evidence of SHS exposure [5]. Hospital-initiated tobacco control interventions promote smoking cessation in adults, especially when counseling is combined with nicotine replacement therapy (NRT) [6]. Parents who smoke are receptive to receiving smoking cessation interventions when their child is hospitalized [7]. Inpatient pediatric clinicians, however, rarely provide such treatments to parents who smoke $[7,8]$.

Pediatric-based smoking cessation interventions in a variety of care settings may be effective in helping parents quit, but barriers have prevented further adoption and sustainability of such practices [8-10]. Time, logistical issues, record-keeping challenges, scope of practice concerns, and lack of insurance reimbursement are cited as barriers to counseling and prescribing NRT [11]. To address these concerns, professional organizations have adopted policy statements and clinical guidelines that underscore the importance of all clinicians addressing tobacco smoke exposure, including recommendations that pediatricians provide counseling and treatment to adults who expose their children to SHS [11-13].

Electronic health records (EHRs) and clinical decision support (CDS) systems may improve the quality and standardization of clinical interventions for tobacco use [14]. CDS systems that support tobacco treatment for hospitalized smokers are feasible and accepted by adult clinicians [15]. In one pediatric primary care setting, use of EHR modifications and brief training to support smoking cessation treatment was associated with higher rates of counseling and quit-line referrals for parents who smoked [16]. The feasibility, acceptability, and usability of a parental tobacco treatment clinical decision support system in an inpatient pediatric setting has not been reported.

\section{Objectives}

Our objective was to create and evaluate the feasibility, acceptability, and usability of a CDS tool to help pediatricians provide smoking cessation counseling and treatment to parents who smoke whose children are hospitalized. At our institution, there was no systematic baseline approach to providing such treatment in the inpatient setting. There was no administrative imperative to address this issue; instead, this was an investigator-initiated project not aligned with any specific administrative priority. We hypothesized that implementing CDS would prompt pediatric residents to initiate smoking cessation treatment for parents who smoke.

\section{Methods}

\subsection{Study Protocol}

This is a mixed method study of first-year pediatric residents, incorporating focus groups, EHR utilization data, and surveys. The intervention, called the tobacco treatment CDS tool, was developed from April to May 2015. Once the intervention was developed, the single-armed, prospective portion of the study was conducted from June to August 2015.

\subsection{Setting and Study Population}

This study was conducted on one inpatient unit at The Children's Hospital of Philadelphia. The inpatient unit has 20 beds, and treats predominantly infant and toddler admissions. In Pennsylvania, approximately $21 \%$ of the adult population smokes cigarettes [17]. Eligible primary subjects included all first-year pediatric residents who rotated through the unit from May to August 2015. Five first-year residents rotate through the unit every month. All residents involved in the prospective study arm had just started their intern year. We excluded only those who declined to participate. There was no nursing involvement in the intervention, as we focused on clinicians. 


\subsection{Intervention}

We created the parental tobacco treatment CDS tool using a usability framework approach [18]. This framework involves developing a tool, incorporating input from future users of that tool, followed by inspection of its use [19-21]. We included input from a diverse team comprised of research experts, clinical informatics experts, clinical content experts (all members of the study team), and end-users (first year pediatric residents, hereafter referred to as "clinicians") [22]. Additionally, we received feedback about the tool and workflow from various hospital committees, including the CDS Committee, Therapeutics Standards Committee, and Clinical Care Committee. We performed focus groups with end-users of the tool from May to June of 2015 to further inform development of the intervention. Questions focused on barriers to current practice and workable solutions to overcome these barriers and problems. End-users and informatics experts emphasized a CDS tool that fit within clinician workflows combined with simple, easy-to-follow treatment guidance steps.

The CDS tool itself was developed using an iterative process of design, testing, and revision. We used standard tools within the vendor system (Best Practice Advisory) as opposed to something completely de-novo. The content for prompts and actions was driven primarily by workflow analysis and CDS design principles $[23,24]$. We carefully considered what information was needed at specific points in the workflow and what actions we expected the clinicians to take and built the tool accordingly. We also wanted to ensure that the tool was not too time-intensive, as clinicians are already busy with many other tasks in the EHR.

The final intervention was modeled on a comparable intervention developed for adult settings, adhering to evidence-based guidelines $[15,25]$. At our children's hospital, we do not have an inpatient smoking cessation counseling program. Our goal was to use a CDS tool to facilitate a brief intervention targeted at parents that involved referral to the Pennsylvania Free Quitline combined with prescription of nicotine replacement therapy. Thus, the tobacco treatment CDS tool within the EHR (EpicCare ${ }^{\oplus}$, Epic Sytems, Inc, Verona, WI, USA) included the following basic capabilities (see -Figure 1: Main Screen for Parental Tobacco Treatment CDS Tool):

1. Appear for clinicians as a "Best Practice Advisory" when a pediatric patient was identified as exposed to secondhand smoke, as documented by a nurse or previous clinician in a separate, discrete field. The advisory was within the admission, rounding, and discharge workflows, and it was non-interruptive (meaning it could be bypassed without any action taken). The advisory appeared with the header "suggestion" and was green in color to further indicate its suggestive and proactive intention.

2. Prompt to ask the parent/caregiver (hereafter referred to as "parent") about smoking and interest in quitting.

3. Add "Secondhand Smoke Exposure" to the patient's problem list in the EHR.

4. Add information to the discharge instructions, including referral to the Pennsylvania Free Quitline for parents to contact for additional assistance, directions on NRT use (if prescribed), and information to help maintain a smoke free home and car.

5. If the parent was present and interested in quitting:

6. Link to a NRT prescription form, for the gum or patch, in an electronically fillable pdf format, with dosing guidance ( $>$ Figure 2 ).

7. Link to document, within the "Secondhand Smoke Exposure" problem, if NRT was prescribed ( $>$ Figure 3).

To facilitate documentation compliance for smoking status, an additional non-interruptive alert was implemented such that if there were no documentation about a patient's smoking status or SHS exposure in the EHR, the clinician would be prompted to complete smoking status documentation. This alert would appear in the same areas of the record as the cessation tool. Completion of the tool was optional. The tool itself would continue to appear for clinicians throughout the hospitalization until it was officially used.

One month into the study period, changes in the EHR build based on feedback from this project led to the incorporation of the tool into the medication reconciliation workflow. As end-users emphasized the need for the tool to fit well within their patient care workflow, this feature was added to the intervention ( $>$ Figure 4 ). When clinicians would review patient medications, either during the 
admission or discharge workflow, the tool would notify the clinician the patient was exposed to SHS and prompt treatment for a parent smoker. The tool remained non-interruptive and completion was optional.

All first-year pediatric residents who rotated through the unit during the study period $(n=15)$ received training, approximately 15-30 minutes in length. Training, which occurred in the clinical setting, addressed brief smoking cessation counseling (the " 5 A's" model) [25], prescribing NRT (including relative contraindications to use), and use of the tool.

\subsection{Outcomes}

\section{Feasibility}

Feasibility of the tool was evaluated using EHR utilization data. Available information included the number of inpatient admissions during which a pediatric patient was identified as exposed to secondhand smoke, as well as completion of each part of the tool. Tool use was defined as completing any part of the tool (i.e., adding secondhand smoke exposure to the problem list, referring to the Quitline through the discharge instructions, or prescribing NRT). Information regarding where in the clinician's workflow the tool was used (i.e. during admission, hospitalization, or discharge) was tracked.

\section{Acceptability and Usability}

Pediatric clinician acceptability of the intervention, including suggestions for improvement, was measured using a 20 -item questionnaire developed by the study team. Clinicians completed the questionnaire at the end of the study period. The questionnaire, which took approximately 5-10 minutes to complete, included items assessing advantages and disadvantages of the tool relative to current care, suggested improvements for the tool, as well as a 10-item computer System Usability Scale (SUS) $[26,27]$. The SUS is a reliable, low-cost, and effective tool for assessing physician usability of and satisfaction with a clinical decision support tool [28]. The 10 statements on the SUS use a five-point Likert Scale to measure strength of agreement or disagreement with the statement; the final score ranges from 0 to 100, with high scores indicating increasing usability and satisfaction [29].

\subsection{Statistical Analysis}

Analyses were conducted by using Stata version 13.1 (Stata Corp, College Station, TX). Data are reported with means and proportions as appropriate. Categorical data were compared with a chisquare test. The Children's Hospital of Philadelphia Institutional Review Board approved this study. Clinicians provided written informed consent.

\section{Results}

During the 3-month study period (June-August 2015), 106 hospitalized patients were identified as exposed to secondhand smoke, and the tool was used for $52(49 \%)$ parents of these patients. Child characteristics associated with tool use are shown in Table 1 . Ten out of 15 (67\%) eligible first-year pediatric residents used the tool at least once.

\section{Feasibility}

Of the 52 patients for whom the tool was used, 40 (38\% of total) patients had Secondhand Smoke Exposure added to the problem list, 34 (32\%) parents were referred to the Quitline through discharge instructions, and 15 (14\%) parents were prescribed NRT. In total, 44 (42\%) parents who smoked were referred for additional treatment and/or prescribed NRT. When the tool was used, it was most often accessed during the discharge workflow (see $>$ Figure 5 for tool use workflow and utilization). Documenting SHS exposure and providing information about the tobacco Quitline, but not NRT prescribing, significantly improved after the alert was incorporated into the medication reconciliation workflow ( Table 2 ). 


\section{Acceptability and Usability}

Nine out of 10 (90\%) first-year pediatric residents who used the tool completed the written survey. All clinicians surveyed were satisfied with the tool and found it helpful. The average System Usability Scale score was 85 out of 100 (95\% CI, 76-93, good to excellent range). Clinician responses to open-ended questions generated several clinically relevant themes. Advantages of the tool included reminder to counsel and prescribe NRT (100\%), ease-of-use (89\%), and access to an electronic NRT prescription (33\%). Disadvantages included inability to re-access the tool once it was initially used (33\%), for example if nicotine replacement scripts needed to be reprinted. Participating clinicians preferred more information on additional treatment options, such as additional behavioral counseling resources, to help guide care.

Additionally, residents who did not use the tool were approached by a member of the study team at the end of their rotation to identify barriers to tool use. All five of the residents offered that they were aware of the tool, but they did not directly take care of any patients exposed to secondhand smoke while rotating through the unit.

\section{Discussion}

We conducted this study to determine if clinical decision support would prompt pediatric clinicians to provide smoking cessation treatment for parents who smoke whose children are hospitalized. Our intervention resulted in a high level of pediatric clinician secondhand smoke exposure treatment. The majority of pediatric clinicians used the tool. More than $40 \%$ of parents who smoked were referred to the Quitline and/or prescribed nicotine replacement therapy.

Our adherence to informatics consensus guidelines in clinical decision support system development helped contribute to the creation of a tool that appears feasible, acceptable, and usable. Guidelines emphasize usability as a key component of safe and effective health information technology [30]. With usability in mind, we ensured that the tobacco treatment tool both complemented doctor-patient/family communication around secondhand smoke exposure and tobacco treatment [31] and fit within clinical workflows $[32,33]$. The impact that incorporation of the tool into the medication reconciliation process had on subsequent tool use exemplifies this point. In all, these approaches ensured the tool met the standards of effective CDS systems: appear at the point of care, offer a specific recommendation, and then enable compliance with that recommendation [30, 34]

Our study has several limitations. First, this is a single-armed feasibility study of a small group of first-year pediatric residents on one pediatric inpatient unit. We did not have a comparison group to know the rates of smoking cessation counseling and treatment offered by clinicians who did not use the tool; however, these rates are likely low as there was no systematic approach to providing treatment to parents who smoke prior to the intervention. Second, since use of the CDS tool followed brief smoking cessation treatment training, it is unclear if training alone may have led to similar rates of treatment, though education alone rarely changes behavior. Third, although the approach was associated with high rates of referral and/or direct treatment, further study is needed to determine how results will generalize to other pediatric hospital settings and clinicians. The tool was piloted on a general pediatrics unit; it may not easily translate to other types of settings, even within the same hospital. Fourth, we did not have information on admission or discharge diagnosis, which also may affect generalizability of the intervention. Fifth, our feasibility study involved an intervention targeted on the initial conversation with parents around smoking cessation. While clinician advice has a small effect on decreasing tobacco use, leading to cessation in approximately 3-6\% of patients, [35] future work could combine CDS systems with more intensive counseling programs, which have been shown to be more clinically effective in adults [6]. Finally, we evaluated process measures of referral and treatment as the outcomes of this study. We did not survey parents postdischarge regarding whether they quit and did not use biological samples to confirm parent smoker quit rates. 


\section{Conclusion}

A non-interruptive CDS tool to help inpatient pediatric clinicians provide smoking cessation treatment was feasible, acceptable, and usable. More than $40 \%$ of parents who smoked were referred for additional treatment and/or prescribed nicotine replacement therapy. These promising results suggest that a randomized trial of this approach, including varied inpatient settings and sites and with additional measures of effectiveness such as biologically confirmed parent quit rates, is warranted.

\section{Clinical Relevance Statement}

This study addresses an important knowledge gap, evaluating the role of health information technology in increasing pediatric clinician engagement in helping parents quit smoking for inpatients. This study demonstrated the feasibility, acceptability and usability of a clinical decision support tool within the electronic health record to help inpatient pediatricians provide smoking cessation treatment to parents who smoke whose children are hospitalized. Given the burden of tobacco smoke on children's health, this intervention is a promising model for facilitating pediatrician support of tobacco cessation in inpatient settings.

\section{Conflict of Interest}

The authors declare that they have no conflicts of interest in the research.

\section{Human Subjects Protections}

The study was performed in compliance with the World Medical Association Declaration of Helsinki on Ethical Principles for Medical Research Involving Human Subjects and was reviewed by The Children's Hospital of Philadelphia Institutional Review Board.

\section{Acknowledgments}

None 


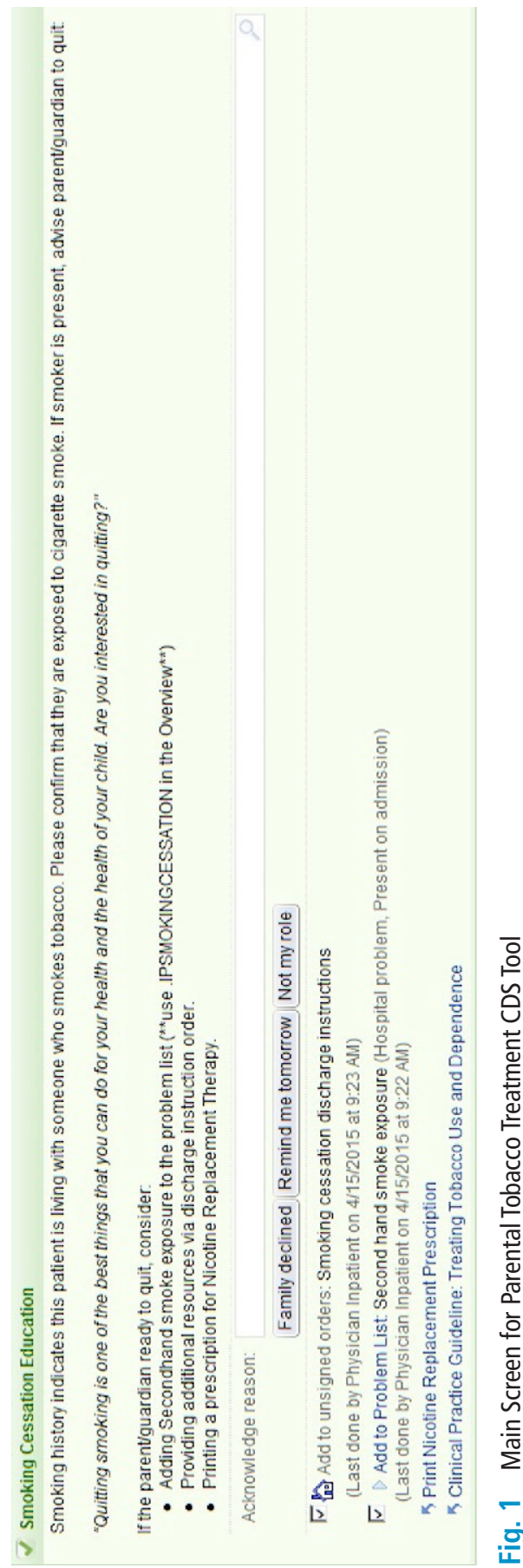




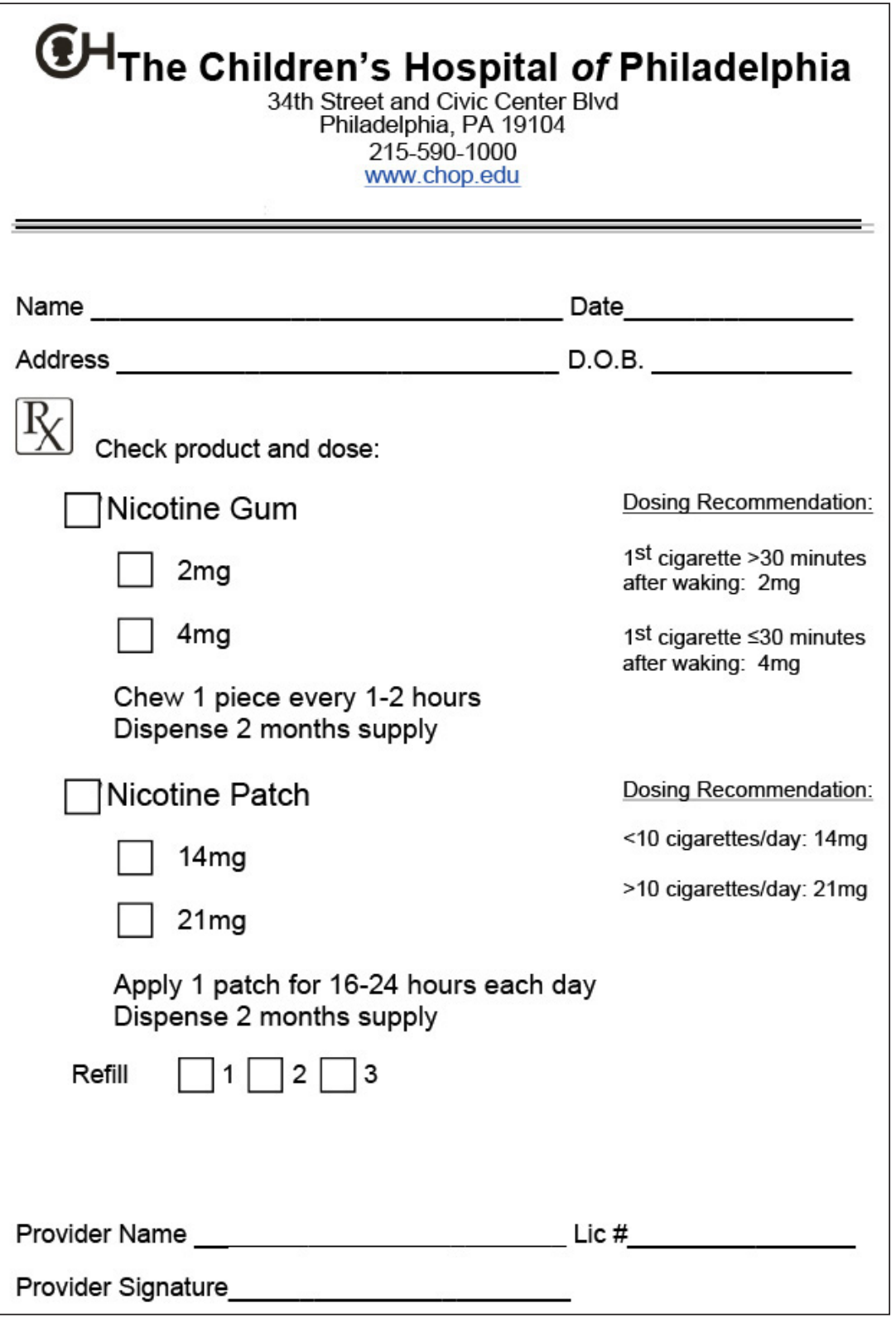

Fig. 2

Nicotine Replacement Therapy Prescription Link 


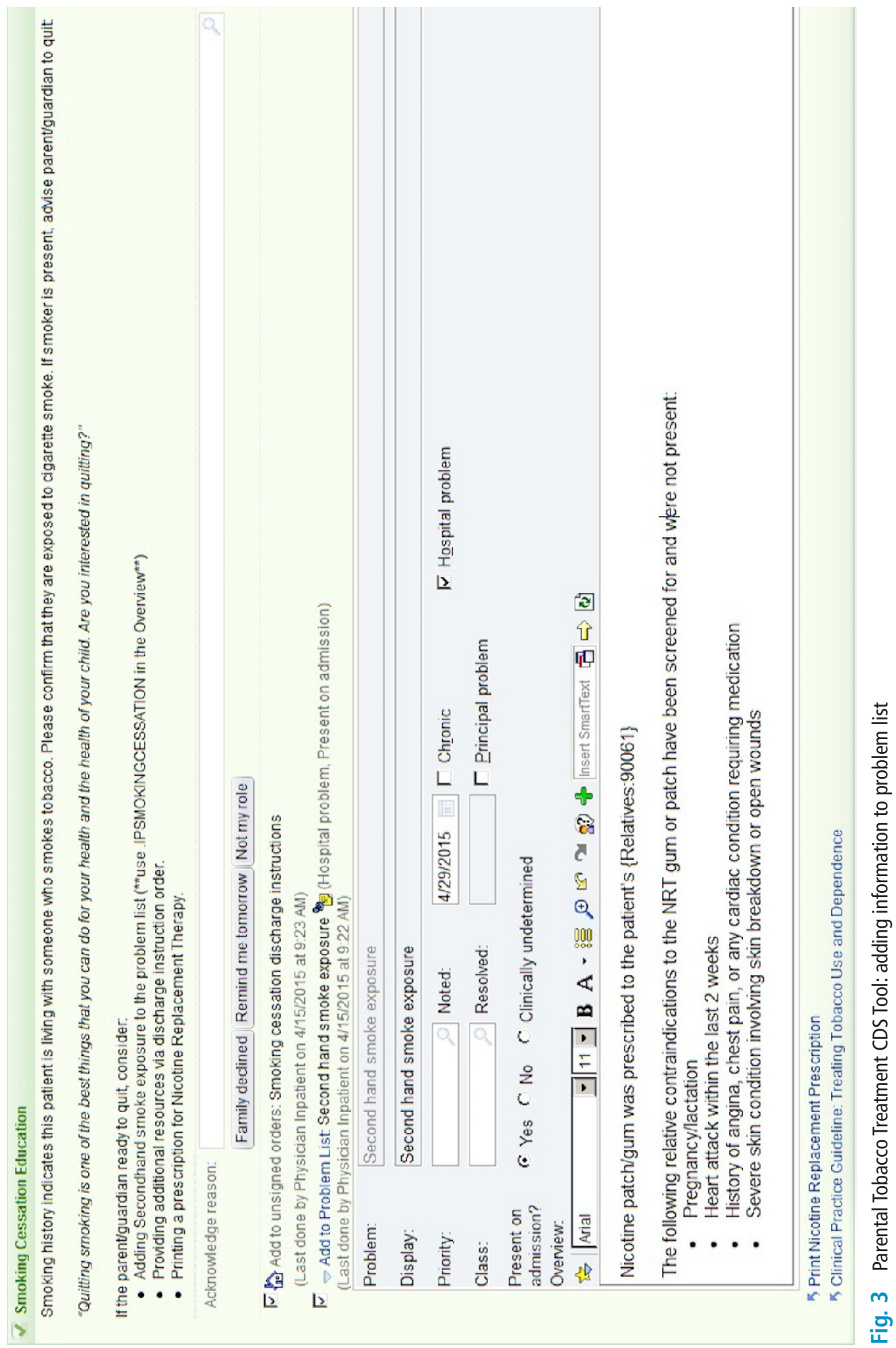




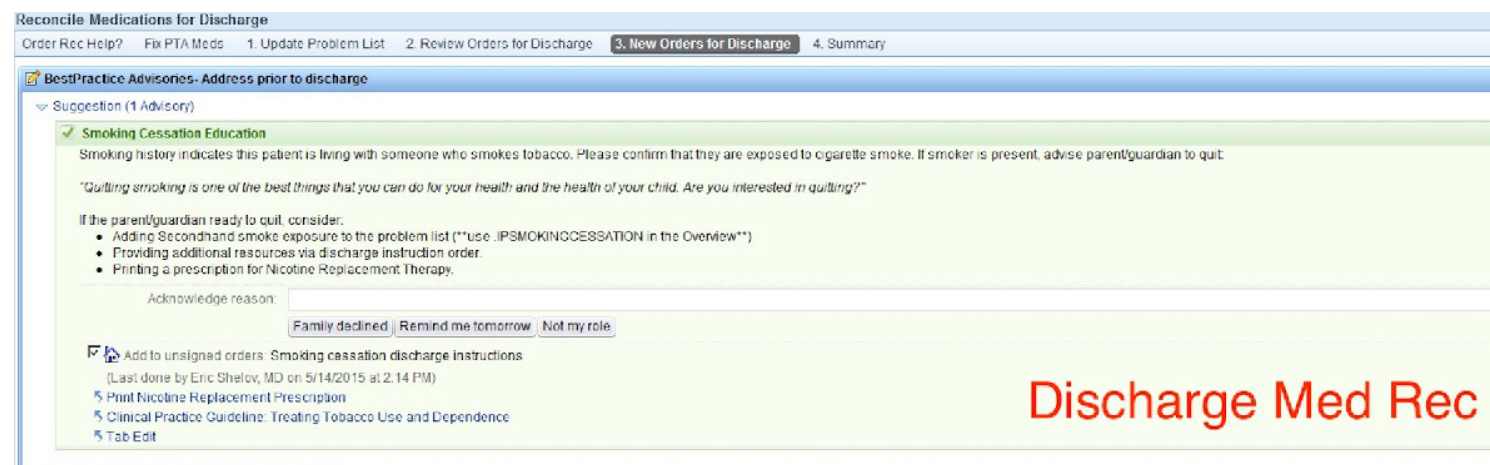

Fig. 4 Tool Incorporation into Medication Reconciliation Workflow

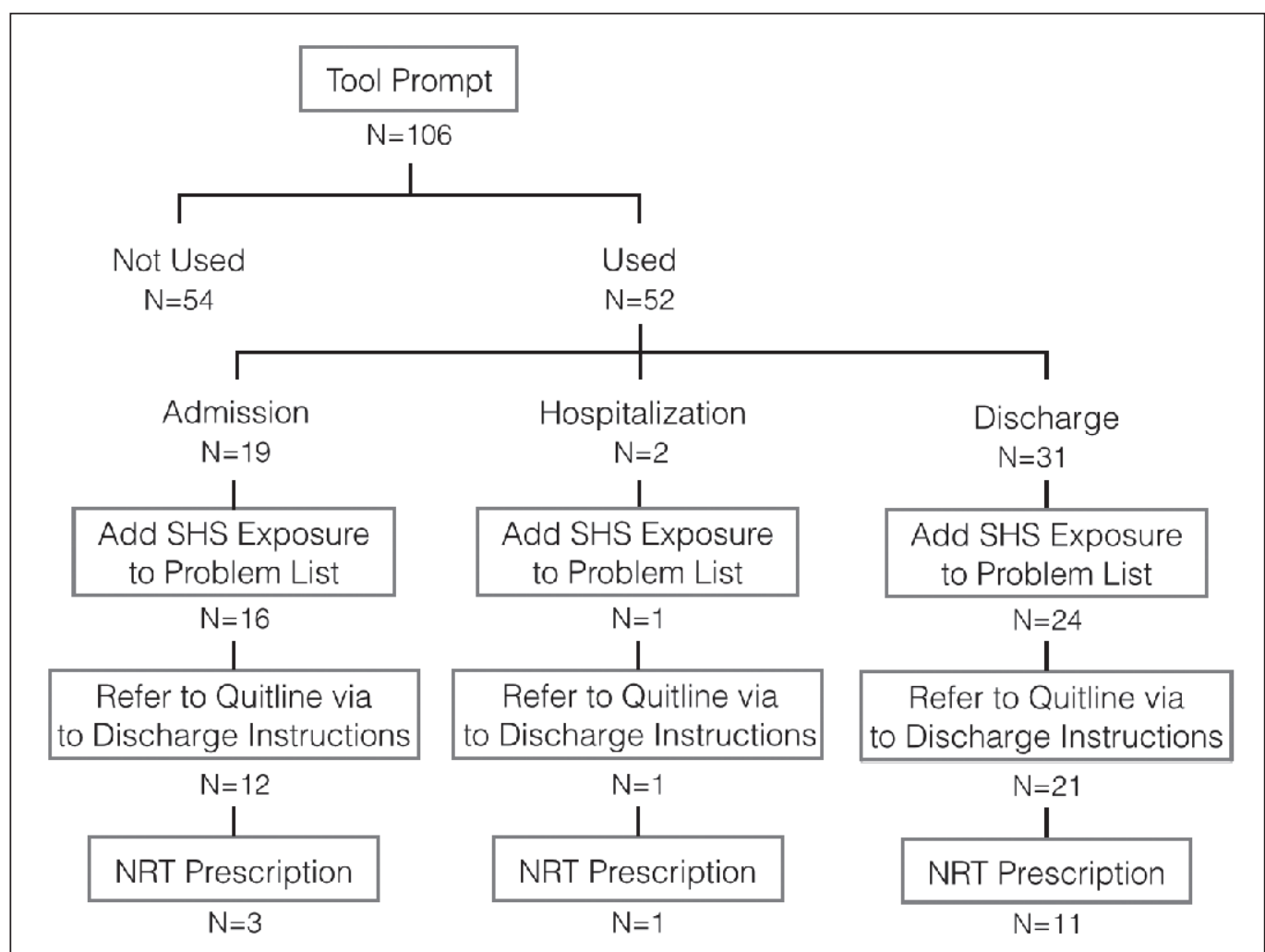

Fig. 5 Parental Tobacco Treatment CDS Tool Use Workflow and Utilization. The parental tobacco treatment CDS tool prompted clinicians in the inpatient setting to counsel and provide treatment to parents who smoke whose children were hospitalized on one inpatient unit $(n=106)$. Boxes in the above figure represent actions taken by clinicians within the tool. All actions are optional; clinicians could ignore the tool completely. For clinicians who used the tool, information was available on where in their workflow they accessed the tool (i.e., during the admission, hospitalization, or discharge workflow). Clinicians could select an action individually without necessarily having to complete another action (e.g., could complete the NRT prescription with or without referring parent to Quitline). Numbers at branch points represent the number of patients/parents for which the action occurred. 


\begin{tabular}{|l|c|c|c|}
\hline & $\begin{array}{l}\text { Tool Used } \\
\mathrm{N}=52(\%)\end{array}$ & $\begin{array}{l}\text { Tool Not Used } \\
\mathrm{N}=54(\%)\end{array}$ & P value* \\
\hline Age (years) & & & 0.98 \\
\hline$<1$ & $26(50)$ & $28(52)$ & \\
\hline $1-5$ & $23(44)$ & $23(43)$ & \\
\hline$>5$ & $3(6)$ & $3(6)$ & 0.57 \\
\hline Gender & & & \\
\hline Female & $23(44)$ & $21(39)$ & $33(61)$ \\
\hline Male & $29(56)$ & & \\
\hline
\end{tabular}

Table 1 Child Characteristics

*via chi square analysis

Table 2 Tobacco Treatment Tool Use Before and After Medication Reconciliation Incorporation

\begin{tabular}{|l|c|c|c|} 
& $\begin{array}{l}\text { Pre-Incorporation } \\
\mathrm{N}=43(\%)\end{array}$ & $\begin{array}{l}\text { Post-Incorporation } \\
\text { N=63 (\%) }\end{array}$ & P value* \\
\hline Added SHS to Problem List & $5(12)$ & $36(57)$ & $<0.001$ \\
\hline $\begin{array}{l}\text { Referred to Quitline via discharge instruc- } \\
\text { tions }\end{array}$ & $4(9)$ & $30(48)$ & $<0.001$ \\
\hline PrescribedNRT & $7(16)$ & $8(13)$ & 0.6 \\
\hline
\end{tabular}

*via chi square analysis 


\section{References}

1. USDHHS: Health Consequences of Involuntary Exposure to Tobacco Smoke: A Report of the Surgeon General. Washington, DC: US Government Printing Office; 2006.

2. Millett C, Lee JT, Laverty AA, Glantz SA, Majeed A. Hospital admissions for childhood asthma after smoke-free legislation in England. Pediatrics 2013; 131(2): e495-e501.

3. Howrylak JA, Spanier AJ, Huang B, Peake RWA, Kellogg MD, Sauers H, Kahn RS. Cotinine in children admitted for asthma and readmission. Pediatrics 2014; 133(2): e355-e362.

4. Jamal A, Homa DM, O'Connor E, Babb SD, Caraballo RS, Singh T, Hu SS, King BA. Current Cigarette Smoking Among Adults - United States, 2005-2014. MMWR Morb Mortal Wkly Rep 2015; 64(44): $1233-1240$.

5. Homa DM, Neff LJ, King BA, Caraballo RS, Bunnell RE, Babb SD, Garrett BE, Sosnoff CS, Wang L. Vital signs: disparities in nonsmokers' exposure to secondhand smoke--United States, 1999-2012. MMWR Morb Mortal Wkly Rep 2015; 64(4): 103-108.

6. Rigotti NA, Clair C, Munafò MR, Stead LF. Interventions for smoking cessation in hospitalised patients. Cochrane Database Syst Rev 2012; 5:CD001837.

7. Winickoff JP, Hibberd PL, Case B, Sinha P, Rigotti NA. Child hospitalization: an opportunity for parental smoking intervention. Am J Prev Med 2001; 21(3): 218-220.

8. Rosen LJ, Noach MB, Winickoff JP, Hovell MF. Parental Smoking Cessation to Protect Young Children:A Systematic Review and Meta-analysis. Pediatrics 2012; 129(1): 141-152.

9. Winickoff JP, Nabi-Burza E, Chang Y, Finch S, Regan S, Wasserman R, Ossip D, Woo H, Klein J, Dempsey J, Hipple B, Weiley V, Murphy S, Rigotti N. Implementation of a parental tobacco control intervention in pediatric practice. Pediatrics 2013; 132(1): 109-117.

10. Winickoff JP, Nabi-Burza E, Chang Y, Regan S, Drehmer J, Finch S, Wasserman R, Ossip D, Hipple B, Woo $\mathrm{H}$, Klein J, Rigotti N. Sustainability of a parental tobacco control intervention in pediatric practice. Pediatrics 2014; 134(5): 933-941.

11. Committee on Environmental Health, Committee on Substance Abuse, Committee on Adolescence, Committee on Native American Child. From the American Academy of Pediatrics: Policy statement--Tobacco use: a pediatric disease. Pediatrics 2009; 124(5): 1474-1487.

12. American Medical Association. H-490.917: Physician Responsibilities for Tobacco Cessation. Adopted by House of Delegates, Chicago, IL: American Medical Association; 2005. Available from: https://www. google.com/

url sa $=t \& r c t=j \& q=\&$ esrc $=s \&$ source $=$ web \&cd $=2 \& v e d=0 C C U Q F j A B \& u r l=h t t p \% 3 A \% 2 F \% 2 F w w w . a m a-$ assn.org\%2Fmeetings\%2Fpublic\%2Fannual05\%2F444a05.doc\&ei=lgNtVPOxDoXbsASX5oC4Dg\&usg=AFQjCNGY8nXkXXtzOILZNpA7TGH2H0aLHw\&sig2=kP8fXhDYnp2XzpE3a3akvA

13. Siu AL. Behavioral and Pharmacotherapy Interventions for Tobacco Smoking Cessation in Adults, Including Pregnant Women: U.S. Preventive Services Task Force Recommendation StatementUSPSTF Recommendation Statement for Interventions for Tobacco Smoking Cessation. Ann Intern Med 2015 Sep 22.

14. Boyle R, Solberg L, Fiore M. Use of electronic health records to support smoking cessation. Cochrane Database Syst Rev 2014; 12: CD008743.

15. Bernstein SL, Rosner J, DeWitt M, Hsiao A, Dziura J, Toll B. Design and implementation of decision support for tobacco dependence treatment in an inpatient electronic medical record. Implement Sci 2015; 10(Suppl. 1): A1.

16. Sharifi M, Adams WG, Winickoff JP, Guo J, Reid M, Boynton-Jarrett R. Enhancing the electronic health record to increase counseling and quit-line referral for parents who smoke. Acad Pediatr 2014; 14(5): $478-484$.

17. Centers for Disease Control and Prevention (CDC). Behavioral Risk Factor Surveillance System Survey Data. Atlanta, Georgia: U.S. Department of Health and Human Services, Centers for Disease Control and Prevention, 2014.

18. Kushniruk AW, Patel VL. Cognitive and usability engineering methods for the evaluation of clinical information systems. J Biomed Inform 2004; 37(1): 56-76.

19.Dumas JS: User-based Evaluations. Edited by Jacko JA, Sears A. In: The Human-Computer Interaction Handbook. Mahwah, New Jersey: Lawrence Earlbaum Associates 2003; 1093-1117.

20. Kastner M, Lottridge D, Marquez C, Newton D, Straus SE. Usability evaluation of a clinical decision support tool for osteoporosis disease management. Implement Sci 2010; 5(1): 96.

21.Daniels J, Fels S, Kushniruk A, Lim J, Ansermino JM. A framework for evaluating usability of clinical monitoring technology. J Clin Monit Comput 2007; 21(5): 323-330. 
22. Trafton JA, Martins SB, Michel MC, Wang D, Tu SW, Clark DJ, Elliott J, Vucic B, Balt S, Clark ME, Sintek CD, Rosenberg J, Daniels D, Goldstein MK. Designing an automated clinical decision support system to match clinical practice guidelines for opioid therapy for chronic pain. Implement Sci 2010; 5(1): 26.

23. Osheroff J, Teich J, Levick D, Saldana L,Velasco F, Sittig D, Rogers K, Jenders R. Improving Outcomes with Clinical Decision Support: An Implementer's Guide, Second Edition. 2 edition. Chicago, IL: HIMSS Publishing; 2012.

24. Fiks AG. Designing computerized decision support that works for clinicians and families. Curr Probl Pediatr Adolesc Health Care 2011; 41(3): 60-88.

25. Fiore MC, Jaén CR, Baker TB, Bailey WC, Benowitz NL, Curry SJ, Dorfman SF, Froelicher ES, Goldstein MG, Healton CG, Henderson PN, Heyman RB, Koh HK, Kottke TE, Lando HA, Mecklenburg RE, Mermelstein RJ, Mullen PD, Orleans CT, Robinson L, Stitzer ML, Tommasello AC, Villejo L, Wewers ME, Murray EW, Bennett G, Heishman S, Husten C, Morgan G, Williams C, Christiansen BA, Piper ME, Hasselblad V, Fraser D, Theobald W, Connell M, Leitzke C. Treating Tobacco Use and Dependence: 2008 Update. Clinical Practice Guideline. Rockville, MD: U.S. Department of Health and Human Services. Public Health Service; 2008.

26. Brooke J. A quick and dirty usability scale. In: Jordan PW, Thomas B, Weerdmeester BA, McClelland AL, editors. Usability evaluation in industry. London: Taylor and Francis; 1986.

27.Lewis JR. IBM Computer Usability Satisfaction Questionnaires: Psychometric Evaluation and Instructions for Use. Int J Hum-Comput Interact 1995; 7(1): 57-78.

28. Tsopra R, Jais J-P, Venot A, Duclos C. Comparison of two kinds of interface, based on guided navigation or usability principles, for improving the adoption of computerized decision support systems: application to the prescription of antibiotics. J Am Med Inform Assoc JAMIA 2014; 21(e1): e107-e116.

29. Bangor A, Kortum P, Miller J. Determining What Individual SUS Scores Mean: Adding an Adjective Rating Scale. J Usability Stud 2009; (4): 114-123.

30. Middleton B, Bloomrosen M, Dente MA, Hashmat B, Koppel R, Overhage JM, Payne TH, Rosenbloom ST, Weaver C, Zhang J. Enhancing patient safety and quality of care by improving the usability of electronic health record systems: recommendations from AMIA. J Am Med Inform Assoc 2013; 20(e1): e2-e8.

31.Fiks AG, Alessandrini EA, Forrest CB, Khan S, Localio AR, Gerber A. Electronic medical record use in pediatric primary care. J Am Med Inform Assoc 2011; 18(1): 38-44.

32. Bates DW, Kuperman GJ, Wang S, Gandhi T, Kittler A, Volk L, Spurr C, Khorasani R, Tanasijevic M, Middleton B. Ten commandments for effective clinical decision support: making the practice of evidencebased medicine a reality. J Am Med Inform Assoc JAMIA 2003; 10(6): 523-530.

33. Garg AX, Adhikari NKJ, McDonald H, Rosas-Arellano MP, Devereaux PJ, Beyene J, Sam J, Haynes RB. Effects of computerized clinical decision support systems on practitioner performance and patient outcomes: a systematic review. JAMA 2005; 293(10): 1223-1238.

34. Kawamoto K, Houlihan CA, Balas EA, Lobach DF. Improving clinical practice using clinical decision support systems: a systematic review of trials to identify features critical to success. BMJ 2005; 330(7494): 765.

35. Stead LF, Buitrago D, Preciado N, Sanchez G, Hartmann-Boyce J, Lancaster T. Physician advice for smoking cessation. Cochrane Database Syst Rev 2013; 5: CD000165. 